\title{
Use of historical data to assess the occurrence of floods in small watersheds in the French Mediterranean area
}

\author{
O. Payrastre ${ }^{1}$, E. Gaume ${ }^{1}$, and H. Andrieu ${ }^{2}$ \\ ${ }^{1}$ Ecole Nationale des Ponts et Chaussées/Centre d'Etudes Eau Ville Environnement, Marne-la-Vallée, France \\ ${ }^{2}$ Laboratoire Central des Ponts et Chaussées/Division Eau, Nantes, France
}

Received: 24 October 2004 - Revised: 9 June 2005 - Accepted: 30 June 2005 - Published: 28 September 2005

\begin{abstract}
The results of an investigation on historical floods in four watersheds of the Aude region in France are presented herein. Using both, archive documents and field investigations, the discharges of the main historical floods could be estimated for a period ranging from one to two centuries. The use of this data, in addition to systematic discharge measurements (continuous series of about 30 years in each case) shows that the calibration of Gumbel and EVII distributions is highly modified by using historical data, despite of the poor accuracy of discharge estimations for historical floods. In some cases, it is also possible, with a simple test using historical data, to exclude a statistical distribution (Gumbel in the presented case) which is not adapted to represent both historical and systematic data samples. Lastly, the historical data gathered highlights important differences in flood intensities among the four studied watersheds, differences that have now to be explained.
\end{abstract}

\section{Introduction}

In the French Mediterranean area, small watersheds of a few dozen square kilometers produce from time to time large floods with extreme peak discharge values. Such flood events are commonly called "flash floods" because of the high speed of water level increase and decrease.

Although such events have been observed several times in the last years (for example in 1999 in the Aude region and in 2002 in the Gard region), it is difficult to estimate their return period. Most of the concerned rivers are ungauged, and the few available measured discharge series are generally too short to estimate accurately flood quantiles corresponding to high return periods. Moreover, information about historical large floods is quite never on hand for these small watersheds.

Correspondence to: O. Payrastre

(payrastre@cereve.enpc.fr)
This paper presents an investigation on four small watersheds in the south east of France, which consisted in gathering historical information about the main past floods and in using this information for statistical analyses. After a short presentation of the four studied watersheds, and of the historical data that could be gathered from archives, the results that are presented herein show how the historical data gathered can be useful for flood risk assessment.

\section{Presentation of the four case studies}

The four studied watersheds are located in the Aude region in the south east of France, and are all tributaries of the Aude river, as indicated in Fig. 1. The catchment areas vary from $42 \mathrm{~km}^{2}$ to $177 \mathrm{~km}^{2}$. These watersheds have been equipped with gauging stations during the 1960's, and continuous discharge series are available for a period of about 30 to 40 years, which is quite rare for watersheds of this size. The region is mountainous: the elevations vary from 150 to 250 meters NGF (Nivellement Général de la France) at gauging stations, to 800 to 1200 meters. The mean slopes of the river beds are about 1 to 2 percents. These watersheds are mainly covered with dense vegetation, only a small part of the surface is under cultivation (mainly vineyards).

\section{Presentation of the historical investigation carried out}

Information concerning the highest floods that occurred in the last two centuries downstream each watershed were gathered both, through the analysis of archive documents and through field investigations. The archive hunting methodology was inspired by the work of Naulet et al. (2001): (a) a detailed list of the potentially interesting archive sources has been first established (it contains 720 references), (b) these references were analysed and 285 documents or groups of really interesting documents were selected and described in detail in a database. A special attention was paid to information about historical flood water levels, cross section shapes, river 


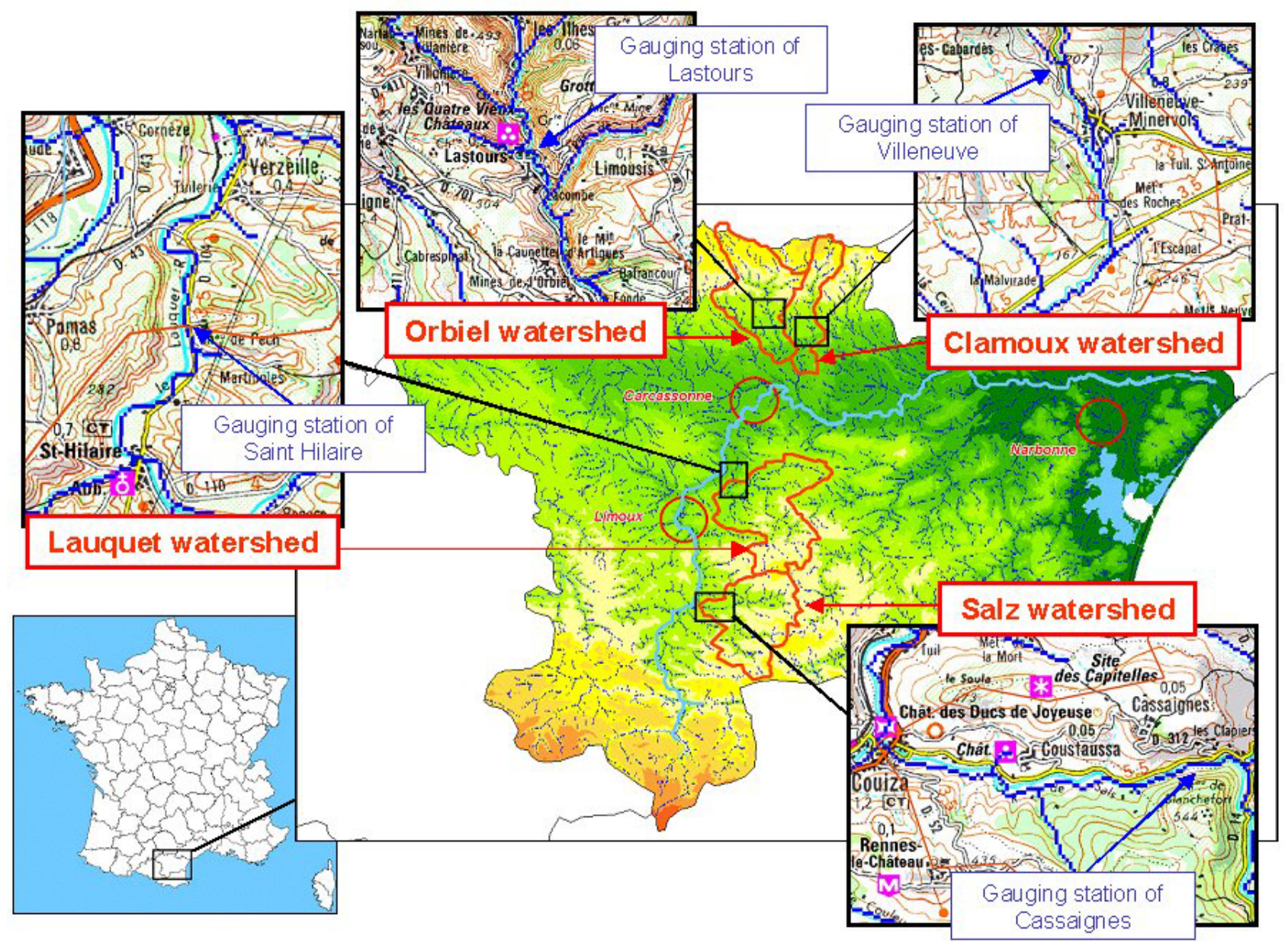

Fig. 1. Location of the four studied watersheds in the Aude region in France. For each watershed, location of the gauging station, nearly which discharges of historical floods were estimated.

longitudinal profiles (see Fig. 2 for an example of historical documentation including information on cross sections and historical water levels). This information was supplemented by field surveys in order to make an inventory of existing flood marks and to measure the current cross sections shapes and longitudinal profiles topography of the rivers and evaluate their possible evolutions over the time.

It was possible, using very simple methods (Manning Strickler equation, or even simple velocity range estimates in the case of non uniform flow), to estimate peak discharges on the basis of the collected data, for most of the historical documented floods. The discharge estimation methods that were used are presented and discussed in Gaume et al. (2004). In each case, a high and a low bound for the possible value of the flood peak discharge was calculated taking into account the various sources of uncertainties: channel effective roughness, mean water level and corresponding wetted area, backwater effects... The range of possible values for the historical peak discharges, estimated on the basis of a hydraulic know-how, is fairly large (see Fig. 4). Gaume estimated it was, in the best cases, within $50 \%$.
As an illustration of the low accuracy of flood discharge estimates, Fig. 3 presents, in the case of the Clamoux watershed, the information available in the section where the discharges of the 1874 and 1891 floods could be estimated. This section corresponds to a bridge, builded in 1868 , under which the high water level of the two historical floods could be found from archives (see the plan presented on Fig. 3). In 1964, the gauging station was installed in the same section. Although this installation caused a few modifications in the cross section shape, one can assume that the hydraulic conditions in this section have not significantly changed during the period of study. The Manning-Strickler equation cannot be used in this section, considering that the basic hypothesis of uniform flow is not verified. Fig. 3 presents the flow velocities that were gauged in this section (after installation of the gauging station), and the corresponding evaluated rating curve: the most important gauged velocity is of $2.16 \mathrm{~m} . \mathrm{s}^{-1}$ and corresponds to a water level of $0.76 \mathrm{~m}$, indicating that the velocities are very high in this section. For higher levels, the rating curve is extrapolated and has no real meaning. Nevertheless, the two historical floods considered correspond to a level of about $2.5 \mathrm{~m}$ at the same scale. Considering all these 

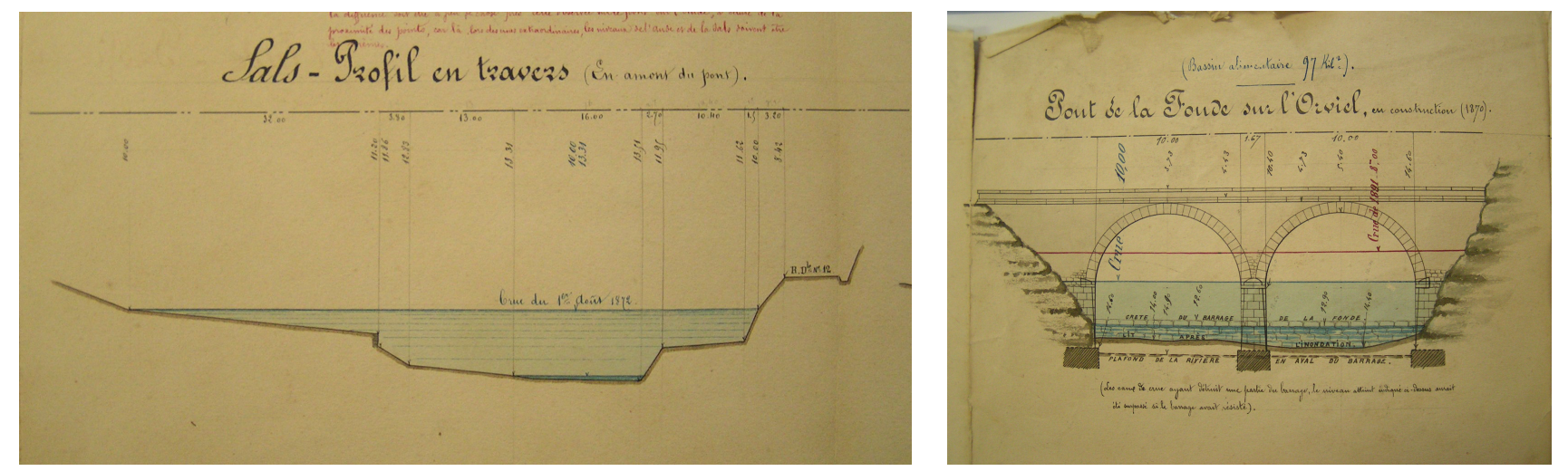

Fig. 2. Two examples of archive documents used for peak discharge estimations. Both give the cross section of the river and the water level of the flood. Depending of the cases, sections can be located under bridges or in free zones.
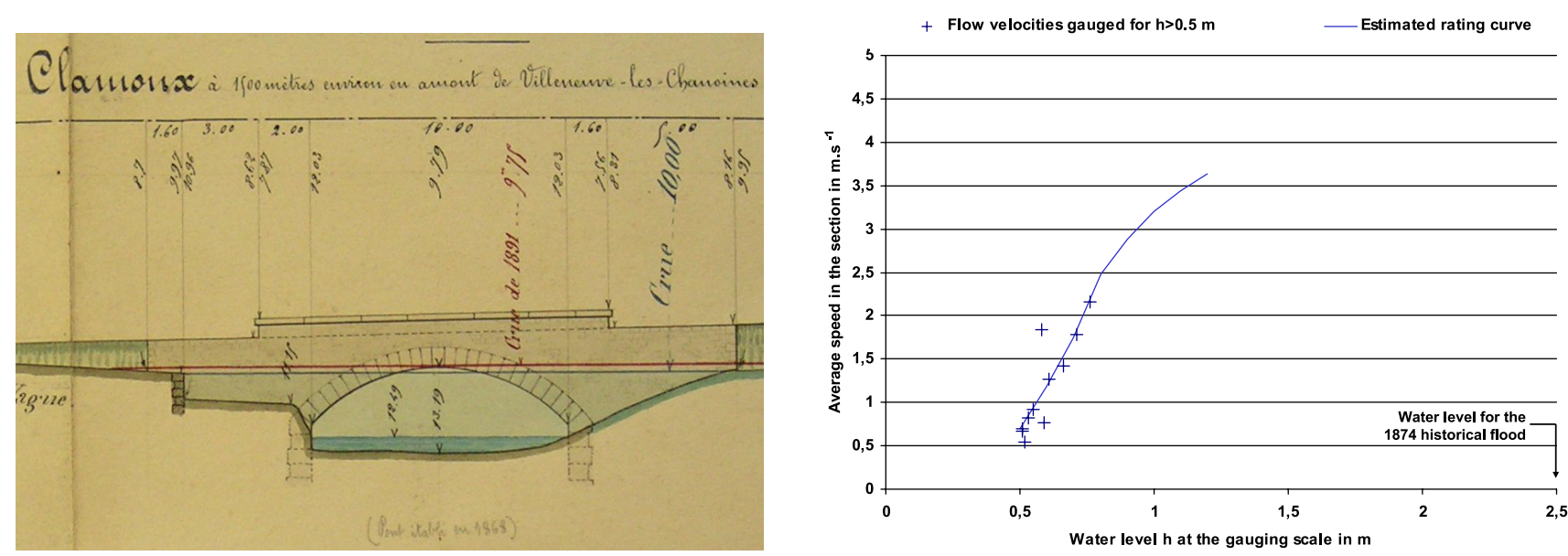

Fig. 3. Informations used for the estimation of peak discharges of the 1874 and 1891 floods. On the left, archive document representing the cross section and the high water levels of the two floods. On the right, speed gaugings carried out in the same section, after installation of the gauging station, indicating that the average speeds in this section are very high.

elements, the possible average velocity for these floods, was considered to be included in a 2.5 to $5 \mathrm{~m} . \mathrm{s}^{-1}$ range, with a most probable value of $3.5 \mathrm{~m} . \mathrm{s}^{-1}$, which is coherent with velocities gauged for lower water levels, as shown in Fig. 3. Moreover, for the 1874 flood, the discharge estimation finally obtained, using this range of average velocity, is coherent with the estimations carried out in other sections (sometimes using Manning Strickler Eq.), as shown in Table 1.

Two examples of flood peak discharge samples finally obtained, including the historical and the systematic measurement period, are presented on Fig. 4. On the basis of the collected data, a perception threshold - minimum discharge value over which all the historical floods are reported and documented - has been determined. This threshold depends on the case study and can vary over the time. Dotted lines on Fig. 4 represent reported flood events for which the peak discharges could not be estimated but were certainly lower than the perception threshold.

Although peak discharges could not be evaluated accurately on the basis of scarce historical data, statistical analy- sis will now reveal if these data sets are of any relevance for flood quantile or return period estimations.

\section{Examples of statistical analysis using historical data}

4.1 Usefulness of historical data for the calibration of statistical distributions

The historical data samples were used in order to calibrate the Gumbel and extreme value type II (Fréchet) distributions, using maximum likelihood estimators. The calibration results obtained using the systematic data either alone or in combination with the historical data were compared.

Four different methods have been tested for the integration of historical data in the likelihood function. These methods correspond to various levels of historical flood inventory exhaustiveness and discharge estimation accuracy:

- method no. 1 (Stedinger and Cohn, 1986): the historical flood peak discharges are supposed to be known with a 
Table 1. Peak discharge estimations carried out, at different sections, for the 1874 historical flood.

\begin{tabular}{|c|c|c|c|c|c|c|}
\hline \multirow[t]{2}{*}{ Section } & \multirow{2}{*}{$\begin{array}{c}\text { Catchment area } \\
\mathrm{S} \text { in } \mathrm{km}^{2}\end{array}$} & \multirow{2}{*}{$\begin{array}{l}\text { Wetted area } \\
\text { in } \mathrm{m}^{2}\end{array}$} & \multirow{2}{*}{$\begin{array}{l}\text { Method used for } \\
\text { velocity estimation }\end{array}$} & \multicolumn{3}{|c|}{ Estimated pseudo-specific discharge $Q / S^{0.8}$} \\
\hline & & & & low bound & most probable & high bound \\
\hline 1 - RD 112 Bridge & 42 & 25.1 & velocity range & 3.1 & 4.4 & 6.3 \\
\hline 2 - Convent Bridge & 42 & 23.1 & velocity range & 2.9 & 4.1 & 5.8 \\
\hline 3 - Upstream RD620 Bridge & 48 & 63.6 & manning strickler & 4.4 & 5.3 & 6.6 \\
\hline 4 - RD 620 Bridge & 48 & 26.1 & velocity range & 2.9 & 4.1 & 5.9 \\
\hline
\end{tabular}
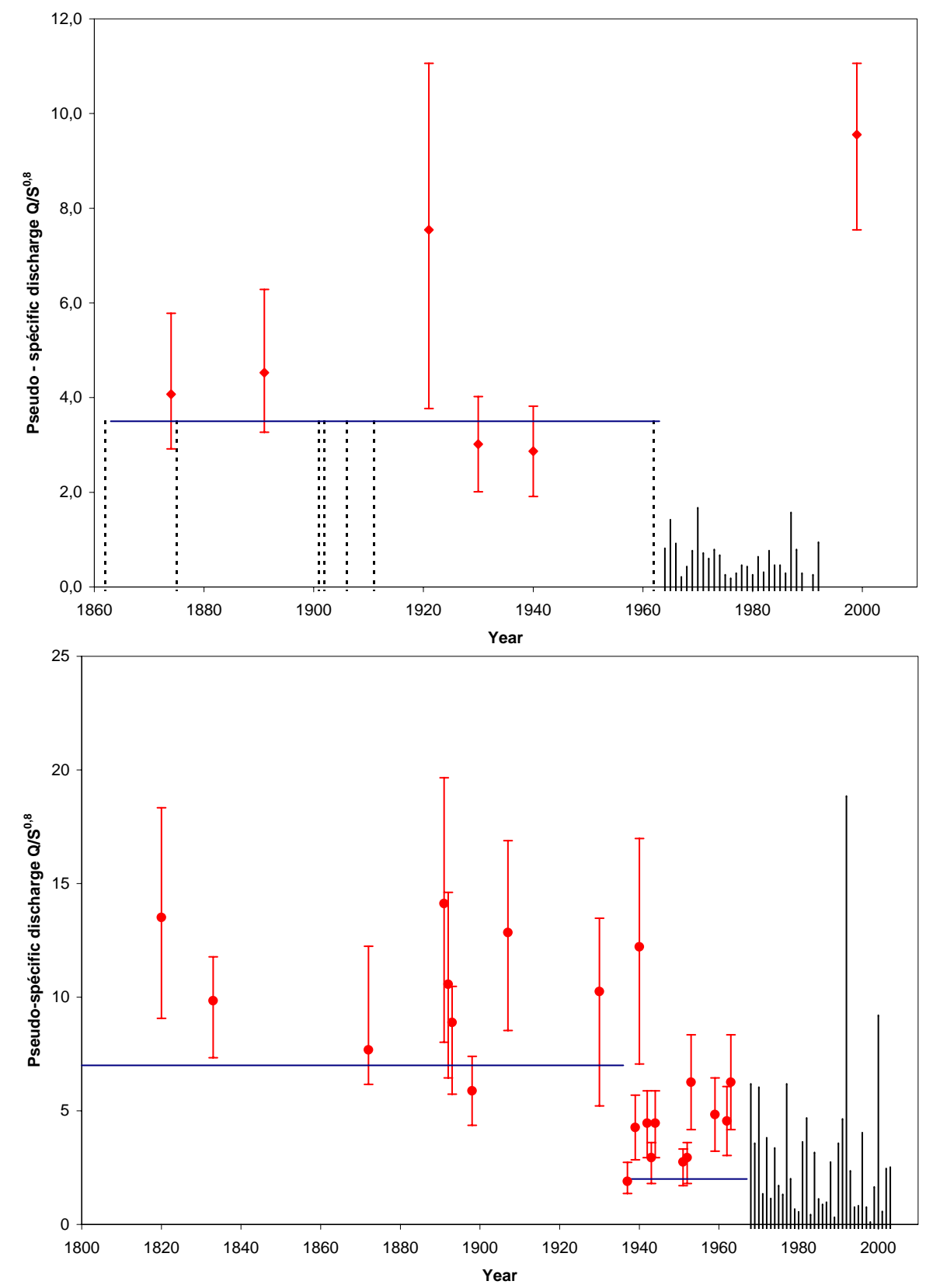

Fig. 4. Example of samples, including systematic and historical floods, that were obtained for the Clamoux (up above) and the Salz (down below) watersheds. Results are presented in pseudo-specific discharge $\left(Q / S^{0.8}\right)$ because of variations of the catchment area at points where historical flood discharge could be estimated. The perception thresholds are represented in plain line for the historical periods. Dotted lines represent historical floods for which discharge values couldn't be estimated: these floods probably not reached the perception threshold. 


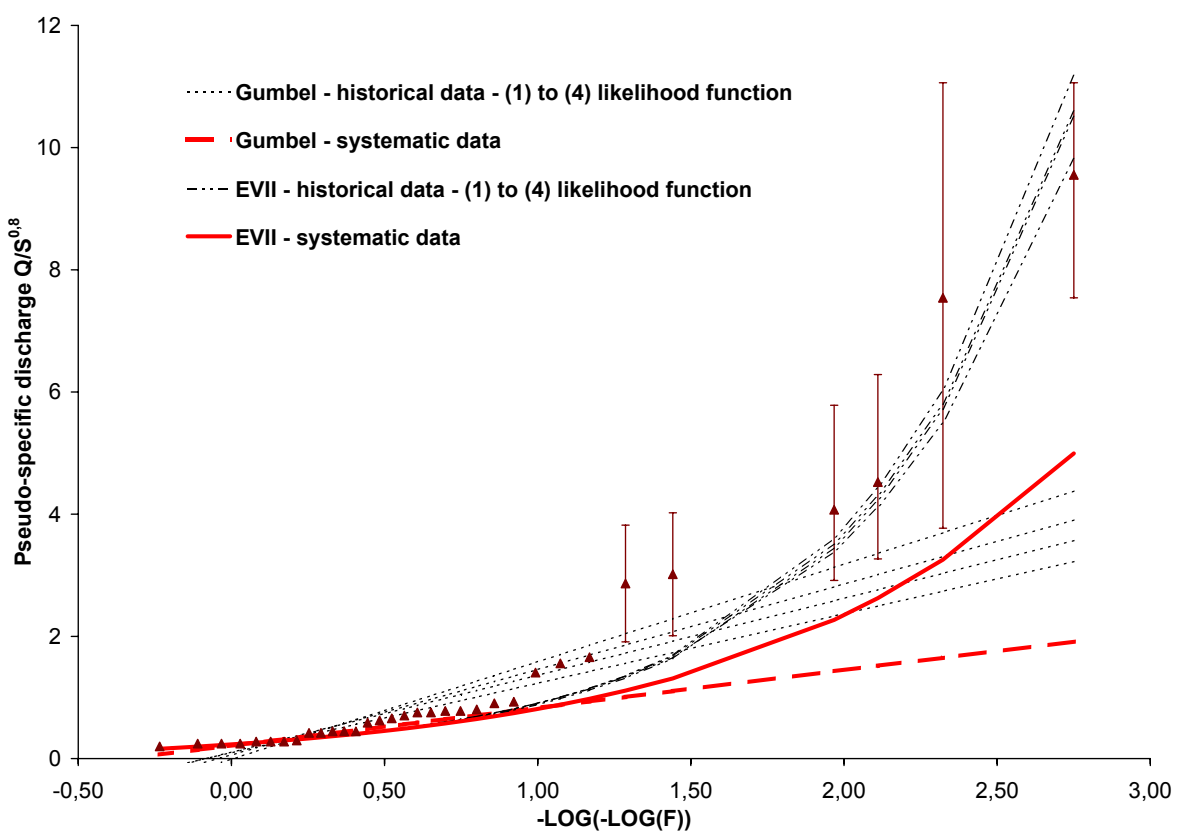

Fig. 5. Empirical probabilities of the observed sample and calibration results of Gumbel and EVII distributions for the Clamoux watershed. The distributions calibrated using only systematic data are represented in bold red lines.

high level of accuracy. For a systematic discharge sample of $s$ years length $X=\left(x_{1}, \ldots, x_{s}\right)$ and a serie of $h$ historical floods discharges $\boldsymbol{Y}=\left(y_{1}, \ldots, y_{h}\right)$ that all exceeded a perception threshold $Y_{P}$ during an historical period of $N_{H}$ years length, the expression of the likelihood function is:

$L\left(\boldsymbol{X}, \boldsymbol{Y}, Y_{P}, N_{H}\right)=F\left(Y_{P}\right)^{N_{H}-h} \cdot \prod_{i=1}^{h} f\left(y_{i}\right) \cdot \prod_{j=1}^{s} f\left(x_{j}\right)$

where $F$ and $f$ are the cumulative density function and the density of probability function for the statistical distribution considered.

- method no. 2 (Stedinger and Cohn, 1986): the historical floods peak discharges could not be estimated and the only available information is the number of times the perception threshold has been exceeded during the historical period. In this case expression of the likelihood function is:

$L\left(\boldsymbol{X}, \boldsymbol{Y}, Y_{P}, N_{H}\right)=F\left(Y_{P}\right)^{N_{H}-h} \cdot\left(1-F\left(Y_{P}\right)\right)^{h} \cdot \prod_{j=1}^{s} f\left(x_{j}\right)(2)$

- method no. 3 (Hosking and Wallis, 1986): the largest historical peak discharge is the only value used in the calibration. It is equivalent to set the perception threshold equal to the maximal historical discharge. It yields to the following likelihood function:

$L\left(\boldsymbol{X}, \boldsymbol{Y}, Y_{P}, N_{H}\right)=F\left(Y_{P}\right)^{N_{H}-1} \cdot f\left(Y_{P}\right) \cdot \prod_{j=1}^{s} f\left(x_{j}\right)$
- method no. 4: historical peak discharge estimations are uncertain and the range of the possible for each historical flood (i.e. $y_{i}^{\text {low }}$ and $y_{i}^{\text {high }}$ the low and high bounds of the interval) is used for the computation of the likelihood:

$$
L\left(X, Y, Y_{P}, N_{H}\right)=F\left(Y_{P}\right)^{N_{H}-h} \cdot \prod_{i=1}^{h}\left(F\left(y_{i}^{h i g h}\right)-F\left(y_{i}^{l o w}\right)\right) \cdot \prod_{j=1}^{s} f\left(x_{j}\right)
$$

The calibration results (examples given in Fig. 5 for the Clamoux watershed and in Fig. 6 for the Salz watershed) show that the incorporation of historical data may modify significantly the adjusted distributions, and the corresponding estimations of return periods and flood quantiles, even for the methods 2 and 4 where the large uncertainties of historical peak discharge estimates are considered. The hundred year return period peak discharge of the Clamoux river estimated on the basis of the Gumbel distribution calibrated on the systematic data set is equal to $33 \mathrm{~m}^{3} \mathrm{~s}^{-1}$. It is between 55 to $75 \mathrm{~m}^{3} \mathrm{~s}^{-1}$ if the historical data are used, depending the calibration method. The same flood quantile is equal to $67 \mathrm{~m}^{3} \mathrm{~s}^{-1}$ if the EVII distribution is calibrated on the systematic data, and to 115 to $121 \mathrm{~m}^{3} \mathrm{~s}^{-1}$ if the historical data set is used for the calibration.

Apart from the effect of historical data on distribution fitting, these results also highlight the influence of the choice of a statistical distribution type. Graphically, the Gumbel distribution appears not to be well adapted to the empirical flood peak distributions, in the case of the Clamoux watershed (see Fig. 5), as well as, to a smaller extent, in the case of the Salz 


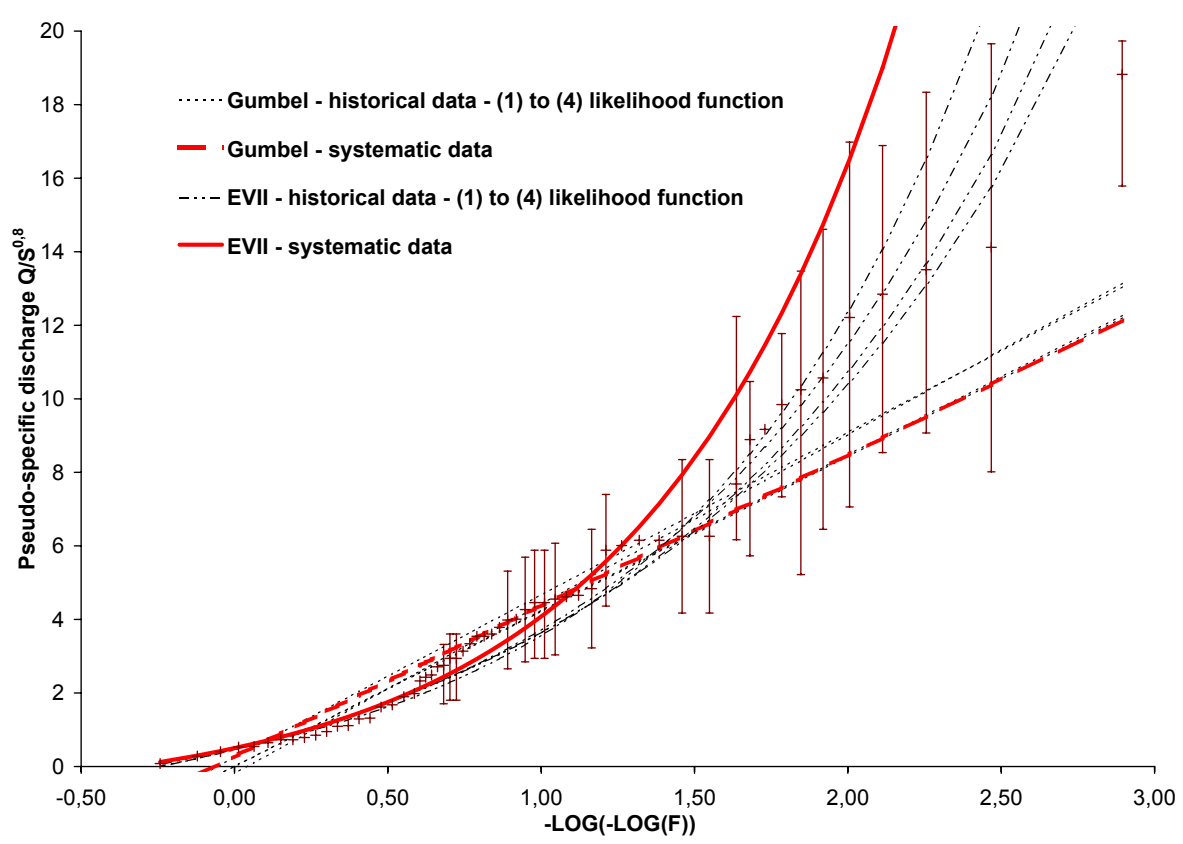

Fig. 6. Empirical probabilities of the observed sample and calibration results of Gumbel and EVII distributions for the Salz watershed. The distributions calibrated using only systematic data are represented in bold red lines.

Table 2. Results of calibration of the Gumbel distribution on the Clamoux watershed. Comparison of the likelihood values of the observed sample and the likelihood distributions obtained from simulations.

\begin{tabular}{|c|c|c|c|c|}
\hline Calibration method & $\begin{array}{l}\text { Historical and systematic } \\
\text { data-method no. } 1\end{array}$ & $\begin{array}{l}\text { Historical and systematic } \\
\text { data-method no. } 2\end{array}$ & $\begin{array}{c}\text { Historical and systematic } \\
\text { data-method no. } 3\end{array}$ & Systematic data \\
\hline $\begin{array}{l}\text { Values of parameters of } \\
\text { the Gumbel distribution } \\
\left(F(Y)=e^{-e^{-\frac{Y-\alpha}{\beta}}}\right. \\
\text { with } Y=Q / S^{0.8}\end{array}$ & $\begin{array}{l}\alpha=0.567 \\
\beta=0.693\end{array}$ & $\begin{array}{l}\alpha=0.561 \\
\beta=0.547\end{array}$ & $\begin{array}{l}\alpha=0.508 \\
\beta=0.494\end{array}$ & $\begin{array}{l}\alpha=0.436 \\
\beta=0.269\end{array}$ \\
\hline $\begin{array}{l}\text { Optimal } \ln (\text { likelihood) value } \\
\text { calculated on the systematic } \\
\text { part of the observed sample }\end{array}$ & -22.2 & -17.3 & -15.3 & -9.3 \\
\hline $\begin{array}{l}\text { Percentage of simulated samples } \\
\text { for which the previous value } \\
\text { was exceeded }\end{array}$ & $0.02 \%$ & $0.1 \%$ & $0.08 \%$ & $68 \%$ \\
\hline $\begin{array}{l}\text { Optimal } \ln (\text { likelihood) value } \\
\text { calculated on the historical } \\
\text { part of the observed sample }\end{array}$ & -34.1 & -22.1 & -17.6 & -83.9 \\
\hline $\begin{array}{l}\text { Percentage of simulated samples } \\
\text { for which the previous value } \\
\text { was exceeded }\end{array}$ & $99.7 \%$ & $99.7 \%$ & $100 \%$ & $100 \%$ \\
\hline
\end{tabular}


watershed (see Fig. 6). It was also the case in the two other case studies. However, in some cases the EVII distribution also doesn't fit perfectly to the observed data set.

The suitability of a distribution for a given data set can be tested. The next part presents such a suitability test and illustrates the usefulness of the additional information that are the historical data in such tests.

\subsection{Statistical distribution suitability tests using historical data}

The main objective of the test procedure presented here is to assess if the fitted distribution and the observed data are coherent. In this test, the likelihood function is used as a measurement tool of the deviation between the observed data set, and samples simulated from the tested distribution. The test is carried out in two steps: first the simulation, from the tested distribution, of samples that have same characteristics as the observed one (same systematic and historical period length, same perception thresholds); then the comparison of likelihood values between simulated samples and the observed one. The distribution of likelihood values, obtained in each case from 5000 random simulated samples (see Fig. 7), represents the distribution of likelihood due to sampling fluctuation. Given this distribution, the hypothesis $H_{0}$ that the likelihood of the observed data set may be explained by sampling fluctuation can be tested. If this hypothesis is rejected, one can conclude that the observed sample does not derive from the tested distribution. This likelihood test can be conducted either on the whole data set or on the historical and systematic data separately. Fig. 7 presents an example of the distribution of likelihood obtained from simulations, for the systematic data set, in the case of the Gumbel distribution calibrated using eq. (1) likelihood function, for the Clamoux watershed. This figure shows that the likelihood value of the observed systematic sample was quite never reached during simulations (exactly for $0.02 \%$ of the 5000 simulations). As a conclusion, in this case, the observed sample is not likely to derive from the tested distribution.

Other results obtained for the Clamoux watershed and the Gumbel distribution are presented in Table 2. The hypothesis $H_{0}$ can not be rejected on the basis of the likelihood of the entire data set, but is rejected with an alpha risk lower than $1 \%$ if the test is carried out separately on the historical and the systematic samples, as soon as the historical data are used either for the calibration or for the test. This result highlights the inadequation of the Gumbel model as far as the flood peak distribution of the Clamoux river is concerned.

The results obtained for the other watersheds cannot be entirely presented here, one can say that in two other case studies, the Gumbel distribution could systematically be rejected, with an alpha risk lower than 5\%, independently of the fitting method that was used (using historical data or not), which confirmed the poor quality of the graphical fittings obtained using this distribution. But on the other hand, in the case of the Salz watershed, presented on Fig. 6, the suitabil-

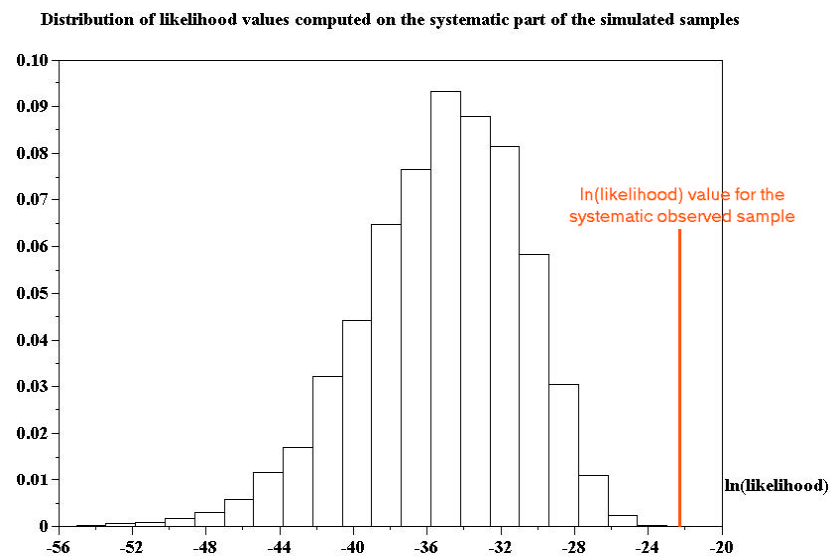

Fig. 7. Results of simulations for the Gumbel distribution calibrated using both historical and systematic data (method no. 1), in the case of the Clamoux watershed: distribution of likelihood obtained from simulations for the systematic data set, and corresponding likelihood value of the observed systematic sample.

ity of the Gumbel distribution could never be rejected, even if the graphical fittings could also appear of poor quality.

The possible non suitability of the versatil 3-parameter EVII model is much more difficult to show. This distribution could never be rejected when historical data was used for its calibration. But in most of the case studies (excepted for the Lauquet watershed), the inadequation of the EVII distribution calibrated on the systematic data could be revealed, by implementing the test procedure on the historical data set: i.e. the parameters of the distribution can not be calibrated accurately using only the systematic data set.

4.3 Flood regimes: comparison of flood peak distributions of various watersheds

The preceding test can be also used to compare the statistical distributions calibrated on one watershed to the data available on an other watershed. It appears that they form two clearly separate groups as far as the distributions of their peak discharges are concerned (see Fig. 8). The differences appear clearly for both, the systematic and historic data sets, and despite the large estimated uncertainties on the historical flood peak discharges. These differences do not depend on the flood scaling method used for the comparison (specific discharge $Q / S$ or pseudo-specific discharge $Q / S^{0.8}$ ). Moreover, the two groups have spatial coherence: the Lauquet and Salz rivers located in the south of the Aude county in a region called Corbières have significantly higher flood peak discharges than the Orbiel and Clamoux rivers located in the north of the county in a region called Montagne Noire. This heterogeneity could be attributed to differences either in rainfall regimes or in the hydrological behaviour of the watersheds. These two hypothesis are under study. 


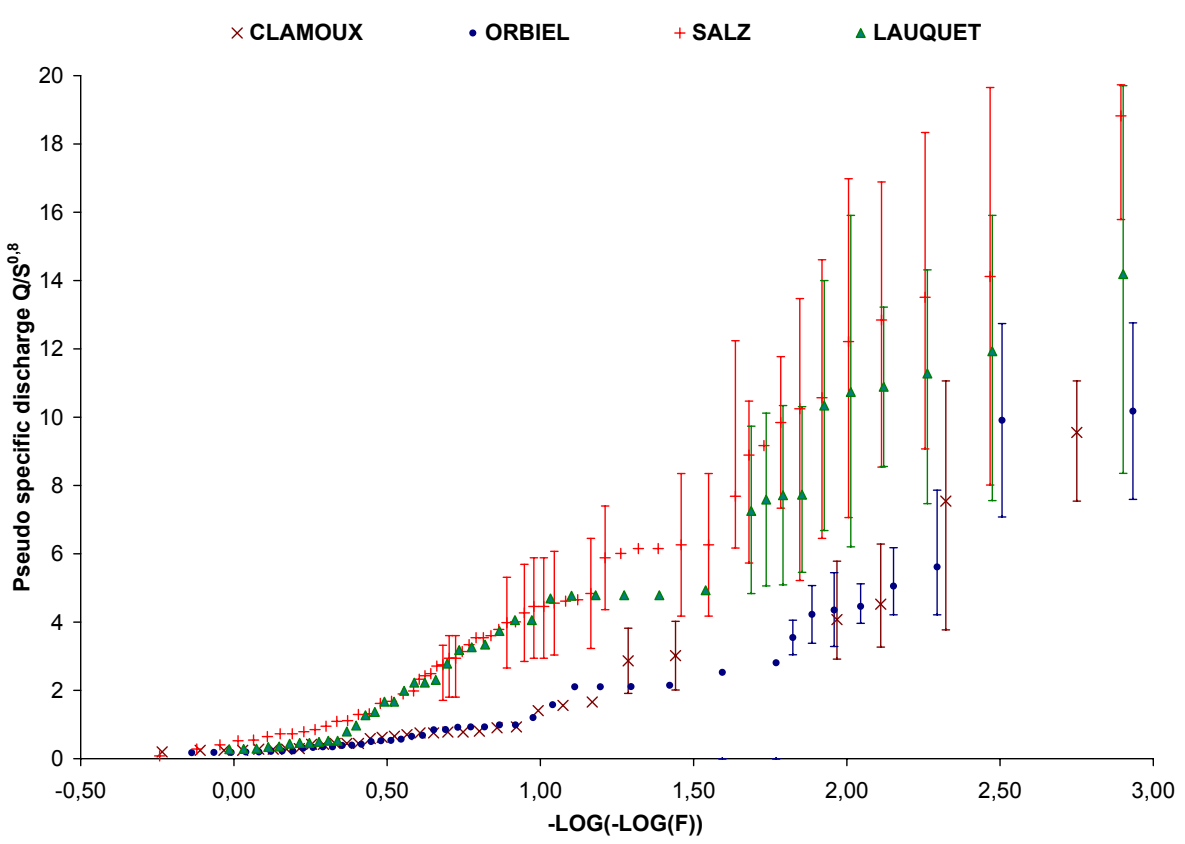

Fig. 8. Empirical probabilities of systematic and historical samples obtained in the four case studies.

\section{Conclusions}

The historical investigations that were carried out in four small watersheds of the French Mediterranean area have shown that it is possible to gather useful information about historical floods that occurred during a period ranging from one to two centuries. On the basis of this data, it was possible to estimate the flood peak discharges and the associated low and high bound of its possible values for the main floods of each studied watershed.

Despite their poor accuracy, the estimated historical flood peak discharges represent a real valuable information for statistical inference purposes as shown by the results presented herein. The calibration of the Gumbel and EVII distributions was highly influenced by the introduction of historical data. Moreover, it was possible, in some cases, to exclude a distribution that appeared not coherent with the observed historical samples: the Gumbel distribution (even calibrated with historical data) in three case studies, and generally the distributions calibrated using only the systematic samples.

The collected historical data showed also clearly that significant differences in the statistical distributions of flood peak discharges of small watershed exist even within a relatively small region, and two sub-regions could be identified in the present case study.
Acknowledgements. The authors thank the Direction Departementale de l'Equipement de l'Aude that provided the systematic data and some useful historical documents. This study received a financial support from the French Ministere de l'Ecologie et du Developpement Durable (RDT program).

Edited by: L. Ferraris

Reviewed by: anonymous referees

\section{References}

Gaume, E., Livet, M., Desbordes, M., and Villeneuve, J.: Hydrological analysis of the river Aude, France, flash flood on 12 and 13 November 1999, J. Hydrol., 286, 135-154, 2004.

Hosking, J. R. M. and Wallis, J. R.: The value of historical data in flood frequency analysis, Water Resour. Res., 22/11, 1602-1612, 1986.

Naulet, R., Lang, M., Coeur, D., and Gigon, C.: Collaboration between historians and hydrologists on the Ardeche river (France). First step: Inventory of historical flood information, Advances in Natural and Technological Research, 17, 113-129, 2001.

Stedinger, J. R. and Cohn, T. A.: Flood frequency analysis with historical and paleoflood information, Water Resour. Res., 22/5, 785-793, 1986. 